\title{
Re-Establishing the Social-Class Order: Restorative Reactions against High-Achieving, Low-SES Pupils
}

\author{
Anatolia Batruch \\ Université de Lausanne \\ Frédérique Autin \\ Université de Poitiers

\section{Fabrizio Butera* \\ Université de Lausanne}

This research investigates a barrier faced by low-SES pupils who are on an upward social mobility trajectory: resistance to their high-achiever status. We hypothesize that, as they disconfirm the usual social-class academic disparities (i.e., high-SES on average outperform low-SES pupils), they threaten the status quo and induce restorative reactions that may hinder their chances of success. Experiment 1 showed that participants remembered less accurately information about pupils when low-SES pupils were presented as outperforming high-SES pupils than when the reverse was true. The errors appeared to be congruent with existing social hierarchies. In Experiment 2, preservice teachers assessed a test supposedly produced by a low-versus high-SES pupil who was presented as being either high or low achieving. The evaluation was harshest when the test was produced by a high-achieving low-SES pupil. These results suggest that people attempt to recreate the social-class academic hierarchy when it is challenged.

\footnotetext{
* Correspondence concerning this article should be addressed to Fabrizio Butera, Université de Lausanne - IP-SSP, Géopolis, CH 1015 - Lausanne, Switzerland. Tel: +4121 6923248 [e-mail: fabrizio.butera@unil.ch].

Anatolia Batruch, Frédérique Autin, Fabrizio Butera, UNILaPS, Institut de Psychologie, Faculté des Sciences Sociales et Politiques, Université de Lausanne, Lausanne, Switzerland. Frédérique Autin is now at Université de Poitiers, France.

This work was supported by the Swiss National Science Foundation (grant CRSII1_141872), and was conducted during Anatolia Batruch's doctorate at University of Lausanne under the supervision of Fabrizio Butera. We wish to thank the members of the Sinergia project "The struggle for competence in academic selection: Social psychological influences on competence threat" for constructive comments on this line of research, and Vincent Pillaud for help in the data collection.
} 


\section{Introduction}

The aftermath of the Great Recession has been more devastating to employment than any other economic crisis since the Great Depression. The increase in unemployment rates related to the crisis still persists in most OECD countries (OECD, 2015). However, this affects disproportionately those with less education (OECD, 2013). During this period of economic uncertainty, a higher level of education thus served as a protection against the risk of unemployment. Yet, according to international surveys, the opportunity to access such education is not equal for all students, as their socioeconomic status (SES) strongly and positively predicts scholastic outcomes (OECD, 2014). In a context where a high educational attainment is more than ever needed to avoid joblessness, it is important to understand the factors leading to social-class inequalities in the access to this form of social protection.

In particular, we propose to investigate the obstacles faced by the low-SES ${ }^{1}$ pupils who could gain access to and thrive in higher education because they are high achievers. These pupils disconfirm the usual social hierarchy in school, with higher SES pupils usually outperforming lower SES pupils. High-achieving lowSES pupils challenge the existing hierarchy and raise the possibility of social change; thus, we argue that they generate an urgency to restore the social order that may result in hindering their chances of success.

\section{Social Hierarchy in the Educational System}

Most groups and organizations are structured as a function of social hierarchies (i.e., formal or informal ranking of individuals or groups), which organize the power dynamics of social relationships (Case, Iuzzini, \& Hopkins, 2012; Magee $\&$ Galinsky, 2008). At times, the hierarchy is explicit, such as the explicit authority of teachers over students. Other hierarchies, however, take on a subtler form, as is the case of pupils in classrooms (Flores, 2007). A major source that signals the pupils' place in the hierarchy is their performance: Following evaluation, pupils are placed on a hierarchical scale that supposedly corresponds to their academic performance (Sabbagh, Resh, Mor, \& Vanhuysse, 2006). Good grades offer considerable rewards, as they are perceived to imply a certain level of merit, which in turn grants the student a certain status, and symbolic as well as material privileges (e.g., good reputation, admission to universities; Felouzis \& Charmillot, 2013).

\footnotetext{
${ }^{1}$ Research has operationalized social class in various manners, as for instance in terms of socioeconomic status (e.g., Croizet \& Claire, 1998), and sociocultural status (e.g., first/continuing generation to attend University; Stephens et al., 2012). The present research focuses on socioeconomic status, but benefitted from the insights of research studying the effects of sociocultural status. See Kraus, Piff, Mendoza-Denton, Rheinschmidt, and Keltner (2012) for a review of these differences.
} 
This stratification further serves as a foundation for future professional opportunities, and in time will determine one's socioeconomic status (Duru-Bellat, Meuret, \& Bègue, 2009).

Thus, schools are the institutions that afford pupils some social position. To preserve social justice and the possibility of social mobility, the educational system is supposed to offer the same chances to every pupil, regardless of social background. In reality, international surveys systematically report more chance for low-SES pupils to underperform, repeat grades, or drop out (OECD, 2014): Academic status is unevenly distributed across social groups, and the academic hierarchy tends to reproduce the social-class hierarchy.

To explain why low-SES pupils systematically find themselves lower in the academic hierarchy, a growing body of research proposes that schools themselves may erect barriers that hinder low-SES pupils' academic performance. Indeed, the educational system conveys norms, values, forms of knowledge, and dispositions that fit higher SES culture. Pupils who grow up in a lower SES context are transmitted a culture that is not rewarded in the academic system; in turn, this greater distance between their own culture and the one needed at school hinders their success (Bourdieu \& Passeron, 1977; Stephens, Markus, \& Phillips, 2014). Moreover, low-SES pupils face from a young age additional daily concerns likely to affect their academic performance, such as the fear of confirming the negative stereotype targeting their social group (Désert, Preaux, \& Jund, 2009). Thus, the education system, through its values and practices, may create a threatening context for low-SES pupils, which results in their under-representation in high-prestige tracks and curricula.

Furthermore, even when low-SES pupils manage to overcome these barriers and attend higher education, they continue suffering from several predicaments (Jury et al., 2017). Successful low-SES students should represent the fulfillment of education's aim of ensuring social mobility and social justice. On the contrary, educational institutions seem to make these students feel unwelcomed, marginalized, and alienated (Nelson, Englar-Carlson, Tierney, \& Hau, 2006; Ostrove \& Cole, 2003; Ostrove \& Long, 2007; Read, Archer \& Leathwood, 2003; Reay, 1998). Compared to high-SES students, low-SES students often report isolation (Rubin, 2012) and a lack of "fit" or belonging (Harackiewicz et al., 2014). Moreover, even at university, these students also struggle with the threat introduced by negative stereotype (Croizet \& Claire, 1998) or unfamiliar cultural norms (Stephens, Fryberg, Markus, Johnson, \& Covarrubias, 2012).

These lines of research document that educational institutions can create conditions that result in the underperformance of low-SES students. However, not all low-SES pupils underperform. We propose that even when low-SES pupils overcome the aforementioned barriers and thrive at school, they face an additional and hitherto unstudied barrier: They are perceived as threatening the social order at school, which triggers hierarchy-restoring reactions in evaluators. To 
restore the academic hierarchy of social classes, evaluators would cognitively and behaviorally undermine their success.

\section{Threat to Social Hierarchy}

Several lines of research posit that individuals tend to justify the status quo and demonstrate the psychological benefits of upholding the existing social arrangements for both advantaged and disadvantaged groups. According to just-world theory, individuals have a basic need to believe that their world is just and people get what they deserve (Lerner, 1980). Evidence contradicting this belief can be threatening and lead to various strategies to reduce this threat. Just-world restoration strategies usually involve some form of reinterpretation of an unjust situation. Individuals can reinterpret either the cause of an injustice, by blaming the victims instead of the situation or the perpetrator; or the outcome of an injustice, by explaining its consequences as positive for the victim (Hafer \& Bègue, 2005).

Similarly, but focusing more on social structure, system justification theory suggests that people tend to support the structure of their system and perceive it as legitimate and necessary, even if the distribution of outcomes is disadvantageous to the self or the group (Jost, Banaji, \& Nosek, 2004; Jost, Pelham, \& Carvallo, 2002). People legitimize social-class inequalities, and system-justifying beliefs can lower support for reducing economic inequalities (Rodriguez-Bailon et al., 2017). Perceiving the status quo as the best arrangement led some authors to hypothesize that disadvantaged group members must not only face obstacles that are embedded in the structure of the social system to achieve equality, but also challenge how people think the system should be structured (Kay et al., 2009). Beside the legitimation of the current social order, motivations to justify the system can elicit restorative reactions against a potential social change, which may further hinder disadvantaged group members.

Regarding restorative reactions, the status incongruity hypothesis (MossRacusin, Phelan, \& Rudman, 2010) proposes that group members who deviate from their group's usual status face a backlash. For example, in the case of gender, women who pursue power violate status expectancies and therefore appear as status incongruent. Both genders consider this incongruence a threat to gender hierarchy, which prompts negative attitudes and behavior as a backlash (Rudman, Moss-Racusin, Phelan, \& Nauts, 2012). In one study, agentic women applying for a university professorship were considered less likeable and hirable than agentic men, even though they were perceived as equally competent. A follow-up demonstrated that such a negative attitude toward agentic women was especially prompted by a threat to the current system. The authors also documented the emergence of active success-hindering behavior toward status-incongruent women. Participants played a computer role-playing game that manipulated the leader's gender and leadership qualities. Participants then chose for the leader clues that varied in 
difficulty, to help him or her in the task. Women with high leadership skills were more likely to be sabotaged (i.e., receive harder clues) than men with comparable competence. In sum, this research shows that low-status individuals with statusincongruent positions suffer from reactions aiming at restoring the status quo.

\section{The Present Research}

Our goal was to investigate whether social-class mobility-in particular the presence of high-achieving low-SES pupils — could be construed as a threat to the social order, and whether the presence of such a threat would elicit an attempt to restore the existing hierarchy. We hypothesized that upward social-class mobility could be perceived as a systemic threat, prompting individuals to recreate the hierarchy.

We decomposed this general hypothesis into two specific hypotheses, tested in two studies. The first hypothesis is that social-class mobility is threatening. We build on the literature showing that when the system hierarchy appears illegitimate, people misremember information about inequalities (Haines \& Jost, 2000). In our first-study participants tried to remember information about pupils in a class in which either high-SES pupils outperformed low-SES pupils (social order) or low-SES pupils outperformed high-SES pupils (social disorder). If low-SES pupils climbing the achievement ladder threaten the status quo, then this condition should interfere with memory more than the social-order condition.

The second hypothesis is that social-class mobility prompts individuals to actively recreate the hierarchy. In Study 2, preservice teachers had to assess a test that was allegedly produced by either a low- or a high-SES pupil, who was either in the high achievers' track or the low achievers' track. We predicted that evaluators would be harshest in their test evaluation with the high-achieving low-SES pupils, thus actively undermining their success.

\section{Experiment 1}

\section{Method}

Participants. Seventy-three psychology students $\left(M_{\text {age }}=20.22\right.$ years, $S D=1.19 ; 63$ women, 10 men) attending a Swiss university participated in our study in exchange for partial course credit. Participant's SES was computed on the basis of parents' level of education. First-generation (parents did not go to university, $N=44$ ) and continuing-generation (at least one parent went to university, $N=28$; 1 unspecified) participants were treated as the low- and the high-socioeconomic group, to follow a procedure frequently used in social psychology studies on social class (Stephens et al., 2012). Participants were 
randomly assigned to one of two experimental conditions (social order vs. social disorder).

Material and procedure. The study was separated into three sections: memorizing information, delay, and recalling information. First, participants were to memorize six school files containing administrative and academic information about 12-year-old pupils: parental occupation, grades, and academic status (whether the pupil had to repeat a year) among other neutral information (i.e., address, date of birth). The academic files contained only information commonly found in files available to Swiss teachers. Manipulation of pupils' SES relied on the parental occupation. Parents of high-SES pupils occupied professional positions (i.e., doctor, lawyer, marketing director) that usually require a university degree and grant high salaries (median annual income 84,500-110,000 Swiss francs; OFS, 2016). Low-SES pupils' parents had occupations (i.e., waitress, construction worker, receptionist) that do not require a university degree and grant lower salaries (median annual income 28,600-67,600 Swiss francs; OFS, 2016). The target pupils ( 3 girls and 3 boys; 3 from a high-SES and 3 from a low-SES background) were all said to be enrolled in the same class.

The six administrative files were identical in both conditions; only pupils' grades were manipulated. In the Swiss educational system, grades range from 1 to 6 (with higher numbers indicating better performance), and pupils have to achieve at least an average of 4 to move on to the next school year. In the socialorder condition, pupils' performances fit the existing social order: The three highSES pupils had good grades (averaging around 5.5), whereas the three low-SES pupils had mediocre grades (around 4). In the social-disorder condition, the pupils' grades were reversed and therefore challenged the educational status quo: The three low-SES pupils had good grades, whereas the three high-SES pupils had mediocre grades. The second part of the study created a delay between the memorizing and the recall of information. In this section, participants had to answer a 5-10-minute questionnaire $^{2}$ for another study about the use of various assessment methods in school.

Finally, participants were told to recall the information about the six pupils. Specifically, participants received a grid with each of the six pupil's name written in the first column. Next to the pupil's name, participants were asked to write down (a) one of the two parents' occupation, (b) the pupil's grades, and (c) whether the pupil had to repeat a year or not. ${ }^{3}$ The total information recalled could range

\footnotetext{
${ }^{2}$ The measures of the questionnaire are not relevant for the hypothesis presented here, and we did not report the results. They are however available upon request from the authors.

${ }^{3}$ Participants were also asked to recall the pupil's number of brother and sisters. We did not report the results, but they are available upon request from the authors.
} 
from 0 (none) to 18 (all pieces of information recalled for the six pupils). Finally, participants were asked some sociodemographic questions, and upon completion they were thanked and debriefed.

\section{Results and Discussion}

Percentage of correct answers. We coded the total amount of correct information recalled, $M=11.25, S D=3.11$. Wrong or no information was coded as an incorrect answer. We then transformed the number of correct items recalled into the percentage of correct answers relative to the total number of possible correct answers (i.e., 18) and analyzed it in a one-way (social order vs. social disorder) ANOVA. Initially, we included participant' SES in the analysis. However, because the results showed no main effect or interaction, this variable was dropped from the final model.

As expected, the social-disorder condition reduced recall of pupils' information, compared with the social-order condition, $F(1,71)=8.02, p=.006$, $\eta^{2}=.10$. The percentage of correct answers was lower when low-SES pupils outperformed high-SES pupils $(M=63.65 ; S D=3.00)$, than when the scholastic hierarchy corresponded to the status quo $(M=75.44 ; S D=2.88)$. Thus, in support to our first hypothesis, the condition that subverted the social order resulted in participants reporting significantly less correct information than in the condition that maintained the status quo.

Supplementary analyses. The above results showed an impairment of recall in the condition with the reversal in social order, showing that evidence contradicting the status quo interfered with participants' memory and suggesting a threatening effect of that condition. However, one might wonder whether the subversion of the status quo by high-achieving, low-SES pupils indeed is threatening or whether the interference comes from some other source. To infer the meaning of the impaired recall, we analyzed the nature of the errors.

Frequency of errors. As mentioned, participants had to report, for each of the six pupils, the information they had read, in each of three categories: one parent's occupations, the pupil's grades, and whether the pupil had to repeat a year. Only one pupil was presented as having repeated a year; this measure showed no variability and was not analyzed. Thus, we analyzed the errors regarding (a) parent occupation and (b) pupil grades: We computed (a) the number of times participants reported a wrong parental occupation and (b) the number of times participants recalled a grade at least 0.5 point higher or lower than the one presented $(0.5$ is the smallest grade point in the Swiss system-e.g., ..., 4.0, 4.5, 5.0, ... ). Because three targets of each SES were presented, participants could give from 0 to 3 wrong answers for both the grades and the parental occupation. We analyzed 
the frequency of errors among participants depending on the targets' SES and the condition.

To account for the high incidence of zero counts in these measures (i.e., no wrong answers; Osgood, 2000), we analyzed the data with Poisson regressions (King, 1988) with the experimental condition (social disorder coded -0.5 , social order coded 0.5 ) and the targets' SES as predictors. To account for the within-subject nature of the SES variable, we specified the model to produce standard errors based on sandwich estimator (Rabe-Hesketh \& Skrondal, 2012). Participants' SES was first included in the model but showed no main effect or interactions and was therefore trimmed from the final model.

We first tested the effect of the social order and the targets' SES manipulations on the frequency of mistakes regarding grades. Results revealed no significant main effect of condition $b=-0.39$, Wald $\chi^{2}(1, N=146)=1.83, p=.18$ or SES $b=0.27$, Wald $\chi^{2}(1, N=146)=1.64, p=.20$. However, their predicted interaction was significant, $b=1.26,95 \%$ CI [0.44; 2.07], $S E=0.42$, Wald $\chi^{2}(1$, $N=146)=9.17, p=.003$. To decompose the interaction, we tested the effect of the condition on the frequency of errors in grades for each SES target separately. We analyzed the data with Poisson regressions featuring robust standard errors to control for violation of the assumption that the dependent-variable variance equals its mean (Cameron \& Trivedi, 2009).

Concerning low-SES targets, more participants made mistakes in recalling the grades in the condition where low-SES grades exceeded those of high-SES pupils' (social disorder), in comparison to the condition where low-SES grades were mediocre (social order), as shown in Figure $1, b=-1.02,95 \%$ CI $[-1.76 ;-0.28]$, $S E=0.38$, Wald $\chi^{2}(1, N=73)=7.27, p=.007$, IRR $=.36 ; 95 \%$ CI $[-0.17 ; 76]$. The difference between the Incident Rate Ratio (IRR) and 1 indicates the change in the expected outcome between the two conditions. The IRR change in errors is a $64 \%$ decrease in the social-order condition compared to the social-disorder condition. Errors in the latter condition indicate that participants "remembered" lower grades than the ones low-SES pupils really had. No significant effects of the condition emerged for high-SES pupils' grades, $b=0.24$, Wald $\chi^{2}<1$, n.s.

Testing for the impact of the condition and SES on the number of errors regarding parental occupation, the analysis revealed a significant effect of SES, $b=-0.84,95 \%$ CI $[-1.34 ;-0.34], S E=0.25$, Wald $\chi^{2}(1, N=146)=10.99$, $p<.001$, IRR $=.43,95 \%$ CI $[0.26 ; 0.71]$. More participants made mistakes when recalling the occupation of the low-SES pupils' parents compared with high-SES pupils' parents. If the target student was from a high-SES background, the particpant's incidence rate for incorrectly recalling the parental occupation would be expected to change by a factor of 0.43 (57\% decrease), while holding all other variables in the model constant. However, neither the effect of condition $b=0.22$, Wald $\chi^{2}<1$, n.s., nor the interaction emerged, $b=-0.60$, Wald $\chi^{2}(1$, $N=146)=1.42, p=.23$. 

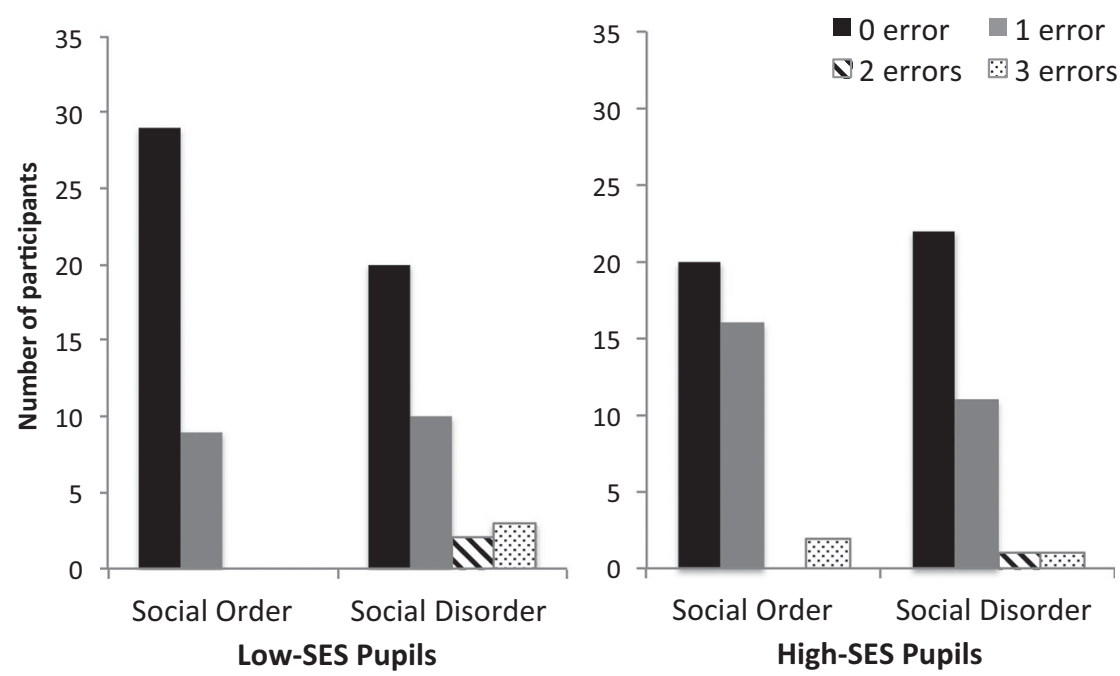

Fig. 1. Experiment 1. Frequency of errors in the recall of pupils' grades as a function of the pupils' SES and the condition.

Thus, when the pupils' performance challenged the status quo (when lowSES pupils outperformed high-SES pupils), recall was less accurate than when the existing hierarchy was maintained. These results support the hypothesis that a disruption of the educational social order may induce a threat that affects participants' recall. Furthermore, exploratory analyses suggested that the elements that were not accurately recalled in the social disorder condition were not misrecalled at random: Participants appeared to misrecall information about these pupils in a manner that re-establishes social hierarchies. Under social disorder, more than in social order, participants frequently misrecalled low-SES pupils' grades by lowering them. In other words, participants had trouble remembering that low-SES pupils had good grades. When they misrepresented the grades of high-achieving, low-SES pupils, they reported lower grades, thereby actively redressing —at least in memory - the breached social order.

\section{Experiment 2}

The first experiment tested the first hypothesis and suggested that the disruption of social order, with low-SES pupils on the top of the achievement ladder, is threatening. The second experiment was then designed to test our second hypothesis that such threatening social-class mobility prompts individuals to actively attempt to recreate the existing hierarchy. Preservice teachers were asked to grade a test that was supposedly produced by a low- versus high-SES pupil, who was 
presented as being in either a high or a low secondary-school track. In Switzerland, where the experiment took place, the higher secondary school track is accessible only to high-achieving pupils (about $40 \%$ in 2014) and gives access to higher education. A low-SES pupil in a track for high achievers benefits from a scarce resource typically benefitting high-SES pupils; this condition should prompt an attempt to actively restore the status quo, in this case by giving lower grades to that pupil.

\section{Method}

Participants. This study was conducted with preservice teachers in a French-speaking Swiss teachers' college, who voluntarily took part in the study during a class $(N=294)$. Each participant was randomly assigned to one experimental condition in the Target's SES (low vs. high) $\times$ Track (high vs. low) between-participants design. Data from eight participants were excluded because they expressed suspicion or were unable to assess the test. Data from 22 participants were excluded because they failed the manipulation checks related to the target's SES (i.e., high-SES target rated 4 and below or low-SES target rated 6 and above on the 7-point scale, $N=8)$ or the track $(N=15)$ or both $(N=2)$. The final sample included 224 women, 26 men, 11 unspecified $\left(M_{\text {age }}=23.07, S D=4.75\right)$.

Material and procedure. Participants received a booklet containing the instructions, tasks, and questionnaire. They first read the cover story explaining that they had to imagine that they were a secondary school teacher, teaching French to 7 th graders and that they would have to assess a dictation test using a specific assessment method.

Manipulation of the track. In the Swiss schooling system, the 7th grade is the first year of secondary school. Pupils have already been streamed towards one of two tracks, namely a lower track that is less demanding academically and directs pupils toward vocational education, and a higher track that is more demanding and gives access to higher education. Yet, change in tracking can still occur at the end of the 7th grade, especially if the pupils do not maintain the required level to remain in the higher track. One half of the participants read that they were teaching French to 7th graders who were in the lower track, whereas the other half read they were teaching to pupils in the higher track.

All participants were then informed they would have to assess the dictation using a norm-based method, based on grades, allowing them to gauge the students' learning, as well as where they stand compared to the norm defining success and compared to the others. An example of a math test graded accordingly was presented. 
Manipulation of the target's SES. After reading the instructions about the assessment method, participants were presented with information about a pupil allegedly belonging to their class. Participants saw the pupil's file and a brief description of the pupil's extracurricular activities. Among neutral information (e.g., date of birth, address), SES was manipulated via the pupil's first name (typical of low vs. high SES; cf. Coulmont, 2011), parental occupation (e.g., waitress vs. architect), and extracurricular activities (e.g., visiting a local amusement park vs. traveling to London).

Dictation test. After reading the target's profile, participants had to assess a dictation test. They were asked to first underline the mistakes and then to give a grade (up to 6 with higher numbers indicating better performance). The test contained 15 obvious mistakes (wrong spelling, wrong verb conjugation, and wrong noun-adjective agreement) and 6 ambiguous mistakes (two possible conjugations or spellings).

Participants also rated the overall quality of the test they had to assess, on a 10-point scale (from 1 very bad to 10 excellent). The booklet ended with manipulation checks. One item asked for the pupil's track. Two items asked for information in the target description (i.e., number of siblings and favorite movie). The last item asked them to rate the target's socioeconomic background (1 highly disadvantaged to 7 highly advantaged). Demographic questions were also collected. Upon completion, participants were thanked and debriefed.

\section{Results and Discussion}

Manipulation check. Participants' perception of the target's socioeconomic status was analyzed in a 2 (track: lower vs. higher) $\times 2$ (target's SES: low vs. high) ANOVA. ${ }^{4}$ As expected, target SES had a main effect, $F(1,264)=$ $123.83, p<.001, \eta^{2}=.31$. The low-SES target was perceived as coming from a less advantaged background $(M=4.19, S D=1.15)$ than the high-SES target $(M=5.73, S D=1.10)$. No other effect reached significance $(F<1)$. This analysis then excluded the 8 participants mentioned in the Participants section.

Total number of mistakes. We performed a 2 (track: lower vs. higher) $\times$ 2 (target's SES: low vs. high) ANOVA on the number of mistakes detected in the test by participants. ${ }^{5}$ Results showed a main effect of track, $F(1,254)=7.07$, $p=.008, \eta_{\mathrm{p}}^{2}=.17$. Participants found more mistakes in the test if the pupil was

\footnotetext{
${ }^{4}$ There is a missing value in the analysis because a participant did not fill in the scales.

${ }^{5}$ There is a missing value in the analysis because a participant did not fill in the scales.
} 


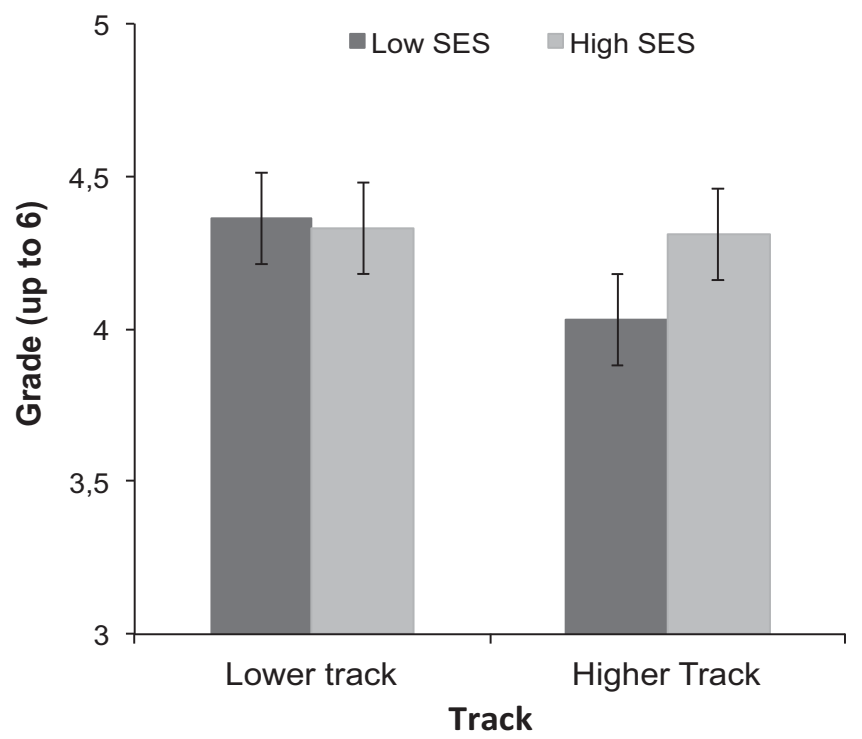

Fig. 2. Experiment 2. Grade attributed to the test as a function of track and pupil's SES, controlling for the number of mistakes found in the test. Error bars represent the $95 \%$ confidence intervals.

in the higher track $(M=11.81, S D=2.54)$ than the lower track $(M=10.95$, $S D=2.54)$. No other effect reached significance $(F<1)$.

Grade. We analyzed grade in a regression with track (lower track coded -0.5 , higher track coded 0.5), target SES (low-SES coded -0.5, high-SES coded 0.5 ), number of mistakes (centered), and all interaction terms as predictors. ${ }^{6}$ The main effect of the number of mistakes was significant, $b=-0.06,95 \%$ CI $[-0.09$; $-0.03], t(232)=-4.47, p<.001, \eta^{2}=.08$, indicating that the more mistakes, the lower the grade. The main effect of the track also reached significance, indicating that pupils in the higher track received a lower grade than pupils in the lower track, $b=-0.17,95 \%$ CI $[-0.32 ;-0.02], t(232)=-2.24, p=.03, \eta^{2}{ }_{p}=.02$.

Finally, the analysis revealed the predicted interaction between target's SES and track, $b=0.30,95 \%$ CI $[0.002 ; 0.61], t(232)=1.98, p=.05, \eta^{2}=.02$. As Figure 2 shows, participants gave lower grades to higher track pupils of low SES $(M=4.03, S D=0.61,95 \%$ CI $[3.88 ; 4.19])$ than if they were high SES $(M=4.31$, $S D=0.56,95 \%$ CI $[4.16 ; 4.47]), b=0.28,95 \%$ CI $[0.06 ; 0.49], t(232)=2.55$,

\footnotetext{
${ }^{6}$ Nineteen participants did not write the grade on the test. Two outliers were removed due to abnormal residuals, uncommon deleted studentized residuals, and Cook's distances.
} 
$p=.01, \eta_{\mathrm{p}}^{2}=.03$. The SES difference in grades was not significant in the lower track $\left(M_{\text {high-SES }}=4.33, S D_{\text {high-SES }}=0.70,95 \%\right.$ CI $[4.18 ; 4.49] ; M_{\text {low-SES }}=4.36$, $S D_{\text {low-SES }}=0.58,95 \%$ CI $\left.[4.21 ; 4.51]\right), b=-0.02,95 \%$ CI $[-0.24 ; 0.19], t(232)$ $=-0.24, p=.80$. No other effect reached significance $(t<1.63 ; p>.10)$.

Rating of the test. The overall evaluation of the test on a 10-point scale positively correlated with the grade, $r=.62 ; p<.001$. An analysis on this related, yet not strictly redundant, indicator of the test evaluation used target track, target SES, number of mistakes detected, and all interaction terms as predictors. ${ }^{7}$ The analysis revealed a significant main effect of the number of mistakes, $b=-0.17$, $95 \%$ CI $[-0.24 ;-0.10], t(247)=-5.10, p<.001, \eta^{2}{ }_{p}=.09$. The interaction between target's SES and track was significant, $b=0.69,95 \%$ CI [0.14; 1.37], $t(247)=2.01, p=.05, \eta^{2} \mathrm{p}=.01$. Participants assessing higher track pupils rated the test quality lower if attributed to a low-SES pupil $(M=5.74, S D=1.22,95 \%$ CI $[5.40 ; 6.08])$ than to a high-SES pupil $(M=6.36, S D=1.33,95 \%$ CI [6.03; $6.70]), b=0.62,95 \%$ CI $[0.14 ; 1.10], t(247)=2.58, p=.01, \eta^{2}{ }_{p}=.02$. The SES difference in test rating was not significant in the lower track $\left(M_{\text {high-SES }}=6.33\right.$, $S D_{\text {high-SES }}=1.64,95 \%$ CI $[5.99 ; 6.68] ; M_{\text {low-SES }}=6.40, S D_{\text {low-SES }}=1.59,95 \%$ CI $[6.05 ; 6.75]), b=-0.07,95 \%$ CI $[-0.55 ; 0.41], t<1, p=.77$. No other effect was significant $(t<1.59 ; p>.11$, marginal track main effect, $t=-1.82, p=.07)$.

The results on the grade and dictation-test rating support our second hypothesis: In the higher track, which only high achievers can access, the test received lower grades and ratings when the pupil was of low-SES rather than of high-SES, even though the actual quality of the dictation test was the same. There was no significant SES difference when the pupils were said to be in the lower track, where general expectations of success are lower. These results suggest that highachieving, low-SES pupils face a behavioral barrier from their evaluators (it is not trivial that the participants in the present experiment were preservice teachers). To restore the academic hierarchy of social classes, evaluators seem to actively diminish the success of the low-SES pupils who are on their way toward social mobility.

\section{General Discussion}

Previous research has documented that pupils from lower SES face a host of structural, cultural, and psychological barriers during their educational trajectory, which often contribute to their underperformance (e.g., Désert et al., 2009; Stephens et al., 2014). The present research aimed to investigate for the first time

\footnotetext{
${ }^{7}$ Two participants did not fill in the rating scale. Three outliers were removed due to abnormal residuals, Cook's distances, and leverage values.
} 
the barriers encountered by those low-SES pupils who do not underperform and sometimes even outperform their high-SES counterparts. We hypothesized that high-achieving, low-SES pupils may (1) threaten the social order and (2) prompt their evaluators to restore the usual educational hierarchy.

To test our first hypothesis, we sought to document that disruption of the education status quo induced a threat. In support, the first experiment revealed that participants presented with a classroom defying the current educational hierarchy (low-SES pupils outperforming high-SES pupils) displayed impaired memories about those pupils, as compared with a condition that maintained the status quo. More specifically, in the social-disorder condition more than in the socialorder condition, participants mistakenly remembered low-SES pupils as being low achievers. This effect cannot be explained by better recall for expectancycongruent information because they misremembered the information. Indeed, two meta-analyses on memory for schema-consistent/inconsistent (Rojahn \& Pettigrew, 1992) and expectancy-congruent/incongruent information (Stangor \& McMillan, 1992) have concluded that, if anything, there is an overall tendency toward better recall for inconsistent information. Thus, the present results could be interpreted as an interference with basic information processing and not as a tendency to remember information consistent with social expectations.

The second experiment tested our second hypothesis that, when confronted with high-achieving, low-SES students, evaluators would try to recreate the status quo by actively hindering the achievement of those pupils. To precisely identify the source of the threat, we manipulated target SES and achievement level in the school system (i.e., higher vs. lower track) to see if participants would specifically diminish the performance of high-achieving, low-SES pupils. Our results confirmed this hypothesis and supported our effects as restoring the hierarchy. Indeed, if the assessments by these preservice teachers were influenced by social expectations (of social class), target's SES would have yielded merely a main effect, regardless of our manipulation of pupil position in the educational hierarchy. Conversely, evaluators could have solely been affected by the presentation of the pupil's prior achievement, which could have been deduced from position in the school's higher or lower track. Our results, however, indicated that the performance of only the high-achieving, low-SES pupils was negatively affected. One specific limitation for this study is that we were unable to collect participants' SES. Therefore we could not assess whether the observed behavior was moderated by the preservice teachers' own socioeconomic background.

The first contribution of our findings is to present a new insight on the mechanisms favoring the perpetuation of the social-class achievement gap. A growing body of literature interested in low-SES underachievement has shown that educational institutions create contexts that directly hinder low-SES students' performance (e.g., Jury et al., 2017). Our research complements this research by providing evidence that reaching a high level of achievement, far from protecting 
low-SES pupils, actually induces additional academic obstacles. Indeed, their success seems to be threatening the social-class hierarchy in schools and provokes cognitive and behavioral reactions to undermine it.

Additionally, a few investigations have examined the backlash behaviors toward low-status group members who defy their usual social position, with a focus on gender hierarchy (Rudman et al., 2012). Thus, the second contribution of our findings is to provide evidence for backlash toward low-SES pupils on an upward social-mobility trajectory. Specifically, evaluators actively under-rewarded the performance of high-achieving, low-SES pupils by lower grades and ratings, thereby interfering with their attempt to climb the academic ladder.

Potential practical implications of the present results relate to the current economic climate, even if such a discussion goes beyond what the data show. As mentioned, since the Great Recession, the economy is unstable, with increased unemployment (OECD, 2015). Previous research showed that displaying information about an instable economy favors backlash against status-incongruent women (Rudman et al., 2012). Combining this research with the present results, we could extrapolate that the current economic climate may trigger particularly negative reactions toward high-achieving, low-SES pupils. Moreover, as noted, since the economic crisis, reaching a high level of education is even more crucial to avoid unemployment than in the past (OECD, 2013). In Switzerland, despite an overall small economic impact of the recession, the Swiss minister of economy has recently proposed to increase educational restrictions to further reduce the number of high-school diplomas delivered (in 2015, 20\% of individuals of the same age group received the diploma) in order to reduce unemployment (Lugon Zugravu, 2016). However, since the recession, youth (25-34 years old) unemployment rates have slightly increased for individuals with below secondary level of education (13.3\% in 2010 vs. $16 \%$ in 2014), but have remained stable for individuals in the same age group with higher education (upper secondary or postsecondary nontertiary: $5.4 \%$ in 2010 vs. $5.1 \%$ in 2014 ; tertiary: $4 \%$ in 2010 vs. $4.6 \%$ in 2014; OECD, 2015). As a result, speculatively, the crisis might increase socialclass inequalities, by fostering negative reactions toward high-achieving, low-SES pupils and then depriving them from a more-than-ever-needed protection against unemployment. The potential consequences of these effects could contribute to increase existing social inequalities in the education system. The experimental nature of our studies limits the external validity of our findings, which would benefit from further examination in order to effectively translate these results into interventions for teachers. In the achievement-gap literature, many interventions are geared toward students to help them improve their academic outcome (Yeager $\&$ Walton, 2011). In light of our results, it seems useful also to address the systemic barriers blocking low-SES students from academic success by devising interventions to raise teachers' awareness of these effects. Particularly in countries practicing early tracking, such as Switzerland, interventions might prevent 
biased academic decisions, which may affect low-SES students' entire academic journey.

One general limitation merits mention. Although our results are consistent with the hypothesis that disruption of the social-class hierarchy is threatening, the evidence of threat in our studies is indirect. The measurement of threat is a classic problem in social psychological research (Scheepers \& Ellemers, 2005). Using explicit measures of threat relies on the assumption that individuals are necessarily conscious of its presence. This assumption is questionable, as behavior can be affected by threat without participants being aware of it (Blascovich, Mendes, Hunter, \& Lickel, 2000). Furthermore, trusting self-report measures can be deceptive, as participants who are the most likely to experience it might also be the least likely to report it as a defense mechanisms (Branscombe, Ellemers, Spears, \& Doosje, 1999). Given the limitations of using explicit measures, we chose to rely on cognitive and behavioral measures that are consistent with a reaction to a threat. One aim of future research in this area will be to measure the threat more directly. For instance, prior work has shown that societal instability and perceived system threat are associated with higher endorsement of conservative policies and support for the status quo (Jost, Glaser, Kruglanski, \& Sulloway, 2003; Bonanno \& Jost, 2006). An interesting venue could be to test the effects of social-disorder exposure on measures of support for the social system to see if disruption of the social-class hierarchy can also lead people to defend the system.

Although the dominant discourse in most educational systems is filled with promises of equal opportunity, when lower SES students manage to overcome academic barriers to go the university, they report facing an unwelcoming environment (Jury et al., 2017). The present research set out to investigate, well before students arrive at university, one of the reasons why high-achieving, low-SES students are not welcomed in their upward social mobility, namely that their success threatens the educational hierarchy. Our studies' pattern of results seems consistent with this reasoning. Taken together, the present findings provide evidence that high-achieving, low-SES pupils threaten the status quo, and that given the opportunity, evaluators may be tempted to undermine their achievement.

\section{References}

Bourdieu, P., \& Passeron, J.-C. (1977). Reproduction in education, culture and society. London, UK: Sage. (Original work published 1970).

Blascovich, J., Mendes, W. B., Hunter, S. B., \& Lickel, B. (2000). Stigma, threat, and social interactions. In T. Heatherton, R. Kleck, M. R. Hebl, \& J. G. Hull (Eds.), Stigma (pp. 307-333). New York, NY: Guilford Press.

Bonanno, G. A., \& Jost, J. T. (2006). Conservative shift among high-exposure survivors of the September 11th terrorist attacks. Basic and Applied Social Psychology, 28, 311-323.

Branscombe, N. R., Ellemers, N., Spears, R., \& Doosje, B. (1999). The context and content of social identity threat. In N. Ellemers, R. Spears, \& B. Doosje (Eds.), Social identity: Context, commitment, content (pp. 35-58). Oxford, England: Blackwell Science. 
Cameron, A. C., \& Trivedi, P. K. (2009). Microeconometrics using Stata. College Station, TX: Stata Press.

Case, K. A., Iuzzini, J., \& Hopkins, M. (2012). Systems of privilege: Intersections, awareness, and applications. Journal of Social Issues, 68, 1-10.

Coulmont, B. (2011). Sociologie des prénoms. Paris, France: La Découverte.

Croizet, J.-C., \& Claire, T. (1998). Extending the concept of stereotype threat to social class: The intellectual underperformance of students from low socioeconomic backgrounds. Personality and Social Psychology Bulletin, 24, 588-594.

Désert, M., Préaux, M., \& Jund, R. (2009). So young and already victims of stereotype threat: Socioeconomic status and performance of 6 to 9 years old children on Raven's progressive matrices. European Journal of Psychology of Education, 24, 207-218.

Flores, A. (2007). Examining disparities in mathematics education: Achievement gap or opportunity gap? The High School Journal, 91, 29-42. doi: 10.1353/hsj.2007.0022

Duru-Bellat M., Meuret D., \& Bègue L. (2009). Les sentiments de justice à et sur l'école. Bruxelles: De Boeck Université. doi:10.3917/dbu.durub.2009.01.0043

Felouzis, G., \& Charmillot, S. (2013). School tracking and educational inequality: A comparison of 12 education systems in Switzerland. Comparative Education, 49, 181-205. doi: 10.1080/03050068.2012.706032

Hafer, C. L., \& Bègue, L. (2005). Experimental research on just-world theory: Problems, developments, and future challenges. Psychological Bulletin, 131, 128-167.

Haines, E. L., \& Jost, J. T. (2000). Placating the powerless: Effects of legitimate and illegitimate explanation on affect, memory, and stereotyping. Social Justice Research, 13, 219-236. doi: 10.1023/A:1026481205719

Harackiewicz, J. M., Canning, E. A., Tibbetts, Y., Giffen, C. J., Blair, S. S., Rouse, D. I., \& Hyde, J. S. (2014). Closing the social class achievement gap for first-generation students in undergraduate biology. Journal of Educational psychology, 106, 375-389.

Jost, J. T., Banaji, M. R., \& Nosek, B. A. (2004). A decade of system justification theory: Accumulated evidence of conscious and unconscious bolstering of the status quo. Political Psychology, 25, 881-919. doi: 10.1111/j.1467-9221.2004.00402.x

Jost, J. T., Pelham, B. W., \& Carvallo, M. R. (2002). Non-conscious forms of system justification: Implicit and behavioral preferences for higher status groups. Journal of Experimental Social Psychology, 38, 586-602. doi: 10.1016/S0022-1031(02)00505-X

Jost, J. T., Glaser, J., Kruglanski, A. W., \& Sulloway, F. J. (2003). Political conservatism as motivated social cognition. Psychological Bulletin, 129, 339-375.

Jury, M., Smeding, A., Stephens, N. M., Nelson, J. E, Aelenei, C., \& Darnon, C. (2017). The experience of low-SES students in higher education: Psychological barriers to success and interventions to reduce social-class inequality. Journal of Social Issues, 73(1), 23-41.

Kay, A. C., Gaucher, D., Peach, J. M., Laurin, K., Friesen, J., Zanna, M. P., \& Spencer, S. J. (2009). Inequality, discrimination, and the power of the status quo: Direct evidence for a motivation to see the way things are as the way they should be. Journal of Personality and Social Psychology, 97, 421-434. doi:10.1037/a0015997

King, G. (1988). Statistical models for political science event counts: Bias in conventional procedures and evidence for the exponential Poisson regression model. American Journal of Political Science, 32, 838-863. doi: 10.2307/2111248

Kraus, M. W., Piff, P. K., Mendoza-Denton, R., Rheinschmidt, M. L., \& Keltner, D. (2012). Social class, solipsism, and contextualism: How the rich are different from the poor. Psychological Review, 119, 546-572. doi:10.1037/a0028756

Lerner, M. J. (1980). The belief in a just world: A fundamental delusion. New York: Plenum.

Lugon Zugravu, L. (2016). Durcir la maturité? La méthode Schneider-Ammann divise Genève. Le Temps. Retrieved from https://www.letemps.ch/suisse/2016/04/25/durcir-maturite-methodeschneider-ammann-divise-geneve

Magee, J. C., \& Galinsky, A. D. (2008). Social hierarchy: The self-reinforcing nature of power and status. The Academy of Management Annals, 2, 351-398. 
Moss-Racusin, C. A., Phelan, J. E., \& Rudman, L. A. (2010). When men break the gender rules: Status incongruity and backlash against modest men. Psychology of Men \& Masculinity, 11, 140-151. doi: $10.1037 / \mathrm{a} 0018093$

Nelson, M. L., Englar-Carlson, M., Tierney, S. C., \& Hau, J. M. (2006). Class jumping into academia: Multiple identities for counseling academics. Journal of Counseling Psychology, 53, 1-14. doi:10.1037/0022-0167.53.1.1

OECD (2013). Education at a glance 2013: OECD Indicators. Paris: OECD Publishing.

OECD (2014). Education at a glance 2014. OECD Indicators. Paris: OECD Publishing.

OECD (2015). OECD Employment outlook 2015. Paris: OECD Publishing.

OFS (2016). Revenu du Travail 2015. Retrieved from http://www.bfs.admin.ch/bfs/portal/

fr/index/themen/03/01/new/nip_detail.html?gnpID=2016-301

Osgood, D. W. (2000). Poisson-based regression analysis of aggregate crime rates. Journal of Quantitative Criminology, 16, 21-43.

Ostrove, J. M., \& Cole, E. R. (2003). Privileging class: Toward a critical psychology of social class in the context of education. Journal of Social Issues, 59, 677-692.

Ostrove, J. M., \& Long, S. M. (2007). Social class and belonging: Implications for college adjustment. The Review of Higher Education, 30, 363-389. doi: 10.1353/rhe.2007.0028

Rabe-Hesketh, S. \& Skrondal, A. (2012). Multilevel and longitudinal modeling using Stata: Vol. 2. Categorical responses, counts, and survival (3rd ed.). College Station, TX: Stata.

Read, B., Archer, L., \& Leathwood, C. (2003). Challenging cultures? Student conceptions of "belonging" and "isolation" at a post-1992 University. Studies in Higher Education, 28, 261-277. doi: $10.1080 / 03075070309290$

Reay, D. (1998). Surviving in dangerous places: Working-class women, women's studies and higher education. Women's Studies International Forum, 21, 11-19. doi: 10.1016/S0277-5395(97)00087-3

Rodriguez-Bailon, R., Bratanova, B., Willis, G. B., Lopez-Rodriguez, L., Sturrock, A., \& Loughnan, S. (2017). Social class and ideologies of inequality: How they uphold unequal societies. Journal of Social Issues, 73(1), 99-116.

Rojahn, K., \& Pettigrew, T. F. (1992). Memory for schema-relevant information: A meta-analytic resolution. British Journal of Social Psychology, 31, 81-109.

Rubin, M. (2012). Social class differences in social integration among students in higher education: A meta-analysis and recommendations for future research. Journal of Diversity in Higher Education, 5, 22-38. doi: 10.1037/a0026162

Rudman, L. A., Moss-Racusin, C. A., Phelan, J. E., \& Nauts, S. (2012). Status incongruity and backlash effects: Defending the gender hierarchy motivates prejudice against female leaders. Journal of Experimental Social Psychology, 48, 165-179.

Sabbagh, C., Resh, N., Mor, M., \& Vanhuysse, P. (2006). Spheres of justice within schools: Reflections and evidence on the distribution of educational goods. Social Psychology of Education, 9, 97118. doi: 10.1007/s11218-005-3319-9

Stangor, C., \& McMillan, D. (1992). Memory for expectancy-congruent and expectancy-incongruent information: A review of the social and social developmental literatures. Psychological Bulletin, 111, 42-61. doi:10.1037/0033-2909.111.1.42

Scheepers, D., \& Ellemers, N. (2005). When the pressure is up: The assessment of social identity threat in low and high status groups. Journal of Experimental Social Psychology, 41, 192-200.

Stephens, N. M., Fryberg, S. A., Markus, H. R., Johnson, C. S., \& Covarrubias, R. (2012). Unseen disadvantage: How American universities' focus on independence undermines the academic performance of first-generation college students. Journal of Personality and Social Psychology, 102, 1178-1197. doi:10.1037/a0027143.

Stephens, N. M., Markus, H. R., \& Phillips, L. T. (2014). Social class culture cycles: How three gateway contexts shape selves and fuel inequality. Annual Review of Psychology, 65, 611-634. doi:10.1016/j.jesp.2012.07.008.

Yeager, D. S., \& Walton, G. M. (2011). Social-psychological interventions in education They're not magic. Review of Educational Research, 81, 267-301. 
ANATOLIA BATRUCH is a PhD candidate from the University of Lausanne, Switzerland, working under the supervision of Fabrizio Butera. She works on the reproduction of social-class inequalities in the educational system. Her work focuses on the use and the effects of merit-based selection practices on the perpetuation of hierarchical status quo at the intergroup level.

FRÉDÉRIQUE AUTIN is an Assistant Professor at the University of Poitiers, France. She is interested in the institutional underpinning of social inequalities in educational contexts. She works on essentialist beliefs about academic difficulty, selection policies and social identity threat, and educational agent's use of practices of selection and social-class reproduction.

FABRIZIO BUTERA is Professor of Social Psychology at the University of Lausanne, Switzerland, as well as Director of the Social Psychology Laboratory. His research interests focus on social influence processes, conflict, and social comparison. He is currently funded by the Swiss National Science Foundation, under the form of a Sinergia grant to study the social psychological influences intervening in academic selection. 